\title{
La sostenibilidad fiscal como limitante de la reparación administrativa de las víctimas de desplazamiento forzado
}

\author{
Fiscal Sustainability as a Constraint on Administrative Reparation \\ for Victims of Forced Displacement
}

Luisa Fernanda García Lozano**
Luis Alberto Castellanos Castillo

Fecha de recepción: 9 de diciembre del 2019

Fecha de aprobación: 25 de julio del 2020

\section{RESUMEN}

El desplazamiento forzado constituye un fenómeno social, económico, político y cultural que ha marcado la historia reciente de Colombia a lo largo del siglo xx y ha dejado graves secuelas en cerca de 7265072 personas víctimas de este flagelo (Unidad para la Atención y Reparación Integral a las Víctimas, 2020). Estas han sufrido las consecuencias propias del desplazamiento y el desarraigo que se desata como consecuencia directa del conflicto armado interno en el que diversos actores armados — como las guerrillas y los grupos de autodefensas, además del mismo Estado— han

\footnotetext{
Este artículo es resultado de la investigación "La aplicación de los modelos de adjudicación en las sociedades posmodernas", financiada por la Vicerrectoría de Investigación de la Universidad Militar Nueva Granada, identificada con el código del proyecto Der-2314-2017, adscrito al Grupo de Investigación de Derecho Público. ORCID: 0000-0003-4319-7547

Citar como: García Lozano, L. F. y Castellanos Castillo, L. A. (2020). La sostenibilidad fiscal como limitante de la reparación administrativa de las víctimas de desplazamiento forzado. Via Inveniendi et Iudicandi, 15(2), 87-130. DOI: https://doi.org/10.15332/19090528/6244

** Abogada por la Universidad Santo Tomás (Colombia); master in Sociology of Law por el Instituto Internacional de Sociología Jurídica de Ońati. Candidata a doctora por la Universidad Nacional de Colombia, Docente asistente de la Universidad Militar Nueva Granada (Bogotá, Colombia). Correo: trevannian@gmail.com, luisa. garcial@unimilitar.edu.co. orciD: https://orcid.org/0000-0003-4319-7547

*** Abogado por la Universidad Nacional de Colombia. Correo: luacastellanosca@unal.edu.co. ORCID: 0000-0003-4690-8965
} 
sido perpetradores en mayor o menor medida de este crimen. Se suma todo ello al escenario de desarraigo y de la perdida de familiares y de los propios bienes, así como a la imposibilidad de continuar o desarrollar un proyecto de vida. Por tratarse de un tema vigente en la agenda pública y la academia, así como en sectores políticos y sociales, este artículo presenta un análisis acerca de cómo el criterio de sostenibilidad fiscal puede llegar a constituir un límite a la garantía de reparación por vía administrativa para las víctimas del desplazamiento forzado en Colombia. Para ello, se tienen en cuenta algunos aspectos relevantes que permiten una aproximación conceptual a la manera en que la insuficiente atención a este grupo poblacional por parte del Estado condujo a que la Corte Constitucional declarara el estado de cosas inconstitucional (ECI) en este aspecto, mediante la Sentencia T-025 del 2004. Se emitieron así diferentes órdenes al gobierno nacional, tanto central como territorial, con el fin de que se adopten las medidas necesarias que permitan, en un primer momento, mitigar los efectos negativos del desplazamiento, como también superar la declaratoria de ECI en el mediano y largo plazo. Todo esto se formula bajo la perspectiva del reconocimiento y la garantía del goce efectivo de los derechos humanos que han resultado conculcados para las víctimas de la violencia en el país.

Palabras clave: desplazamiento forzado, sostenibilidad fiscal, reparación administrativa, goce efectivo de derechos, Corte Constitucional, Estado Social de Derecho (ESD).

\section{Abstract}

Forced displacement is a social, economic, political, and cultural phenomenon that has marked the recent history of Colombia throughout the twentieth century and has left serious consequences in some 7,265,072 people, victims of this scourge (Unidad para la Atención y Reparación Integral a las Víctimas, 2020) who have suffered the consequences of displacement and uprooting as a direct result of the internal armed conflict in which various armed actors - such as guerrillas and paramilitary groups, in addition to the State itself- have been perpetrators to a greater or lesser extent. Additionally, victims have suffered from uprooting and the loss of relatives and property, as well as the impossibility of continuing or developing a life project. Being this a current topic on the public agenda and academia, as well as in political and social sectors, this article presents an analysis of how the criterion of fiscal sustainability can constitute a limit to the guarantee of reparation through administrative channels for victims of forced displacement in Colombia. For this purpose, 
some relevant aspects are taken into account that allow a conceptual approximation to the way in which insufficient attention by the State to this population group led the Constitutional Court to declare an unconstitutional state of affairs in this regard by means of Ruling T-025 of 2004. Different orders were issued to the national government, both central and territorial, in order for it to adopt the necessary measures to initially mitigate the negative effects of displacement, as well as to overcome the unconstitutional state of affairs declaration in the medium and long term. All of this is formulated from the perspective of the recognition and guarantee of the effective enjoyment of human rights, which have been violated for the victims of violence in the country.

Keywords: forced displacement, fiscal sustainability, administrative reparation, effective enjoyment of rights, Constitutional Court, Rule of Law. 


\section{INTRODUCCIÓN}

Son múltiples los factores que propician el desplazamiento forzado en Colombia. Entre los principales generadores de esta situación en la que se viola de manera reiterada el derecho internacional humanitario (DIH), aparecen los grupos armados ilegales. En tal sentido, vale aclarar que, en el caso de los grupos paramilitares, se esconden intereses particulares de ganaderos, narcotraficantes, transnacionales y grandes capitalistas nacionales que, bajo el pretexto de combatir a los grupos guerrilleros, han establecido alianzas con organismos de seguridad del Estado y el ejército en procura de combatir la amenaza subversiva (Comisión Histórica del Conflicto y sus Víctimas, 2015). Puede entonces señalarse que guerrillas, militares, paramilitares, ganaderos, narcotraficantes, esmeralderos y comerciantes, así como empresas nacionales y transnacionales han contribuido, en diferentes proporciones, a provocar el desplazamiento, lo que permite seńalar la existencia de un nexo entre el desplazamiento y la imposición de modelos de acumulación de capital (Bello, 2004; Leaño, 2015).

El reconocimiento del desplazamiento como consecuencia de la violencia y su inclusión como tema humanitario urgente que debía incorporarse en la agenda pública condujeron, hacia 1995, a la expedición del documento Conpes 2804, que trazó las directrices sobre cómo ofrecer asistencia a la población desplazada, en aspectos de prevención y atención humanitaria de emergencia, así como de posibilidades de acceso a programas que permitieran la reintegración a los entornos sociales.

En 1997 llegó el segundo Conpes: 2924, este trae una gran ventaja, la cual hace referencia a la incursión de organizaciones gubernamentales y no gubernamentales para ayudar a la población desplazada y se crean los siguientes puntos de atención: Sistema Nacional de Atención Integral a la Población Desplazada por la Violencia, el Plan Nacional, el Fondo Nacional para la Atención a la Población Desplazada y la Red Nacional de Información, hoy conocida como Acción Social de la Presidencia de la República. (Díaz y Leiva, 2009, p. 8)

En el contexto social y político que se presentaba en Colombia en los 90, la postura de los gobiernos de turno frente al desplazamiento fue de indiferencia. Un esfuerzo por 
ofrecer una salida a los primeros brotes de desplazamiento forzado fue la expedición de la Ley 387 de 1997, mediante la cual se crea el Sistema Nacional de Atención Integral a la Población Desplazada por la Violencia (sNaIPDv).

Entre 1997 y 2011, se adelantó un proceso de configuración de los esquemas de respuesta y arreglos organizacionales y referenciales de política —imágenes del problema (Muller, 2006)_, a partir de los cuales las administraciones públicas, la nación y los territorios, diseñarían, implementarían, evaluarían y reportarían, las políticas que se despliegan para la atención al desplazamiento forzado. Sin embargo, el SNAIPDV no logró consolidar un enfoque sistemático o un esquema de gestión de coordinación intra-e interinstitucional, de manera que se permitiera el logro se sinergias entre los entes responsables y, además, se fijaran políticas que trascendieran el cambio de un gobierno u otro. (Alzate y Rodríguez, 2017, p. 25)

Ante la permanente falta de atención a este grupo poblacional, manifiesta en los continuos reclamos que se seguían presentando por inacción de las entidades estatales, la Corte Constitucional, a través de la Sala Tercera de Revisión, acumuló las tutelas presentadas por 1.150 familias desplazadas y procedió a declarar el estado de cosas inconstitucional (ECI) mediante la Sentencia T-025 del 2004, que se constituyó en sentencia hito sobre ese asunto.

Además de lo decidido por la Corte Constitucional, y a manera de antecedente, esta corporación ya había señalado el alcance que debía otorgárseles a las medidas que los órganos gubernamentales estaban obligados a implementar, dado su carácter de urgencia; en tal sentido,

[...] la Sentencia T-268 de 2003 M.P. Marco Gerardo Monroy Cabra, estableció tres principios, así: 1) el principio de favorabilidad en la interpretación de las normas que protegen a la población desplazada, 2) los Principios Rectores del Desplazamiento Forzado Interno, y 3) el principio de prevalencia del derecho sustancial en el contexto del Estado Social de Derecho. En síntesis, "las medidas especiales a favor de los desplazados facilitan que estos se tornen menos vulnerables, agencian la reparación de las injusticias 
derivadas del desplazamiento involuntario y se orientan a la realización efectiva de ciertos derechos de bienestar mínimo que constituyen la base para la autonomía y el autosostenimiento de los sujetos de desplazamiento”. (García Lozano, 2014, p. 155)

Como complemento a la declaratoria del ECI, la Sala Plena de la Corte Constitucional decidió crear, en abril del 2009, la Sala Especial de Seguimiento a la Sentencia T-025 del 2004. Mediante la expedición de un número significativo de autos de seguimiento, así como de la celebración de audiencias públicas, esta sala ha pretendido consolidar el valor normativo de la Constitución frente a las víctimas del desplazamiento forzado. En tal sentido,

La Corte Constitucional, por medio de la Sala Especial de Seguimiento a la Sentencia T-025 de 2004, sus autos de seguimiento y las audiencias públicas guarda correspondencia con las teorías sobre constitucionalismo democrático de Robert Post y Reva Siegel. Esto significa que la Corte, en búsqueda de garantizar la vinculatoriedad y la autoridad de la Constitución frente a las diversas problemáticas asociadas al desplazamiento forzado, comprende que los debates sobre el contenido de las disposiciones constitucionales deben contar con la participación tanto de las agencias gubernamentales y otros órganos estatales, como de sectores de la sociedad civil como organizaciones académicas, organizaciones de derechos humanos, de víctimas o de aquellas que agrupen población desplazada. (Lozano, Payán, y Ruiz, 2015, pp. 56-57)

De otra parte, un componente que puede ser determinante al momento de hacer efectivo para la población víctima del desplazamiento forzado el goce cabal de sus derechos está relacionado con el criterio de sostenibilidad fiscal, incorporado en la Constitución de 1991 mediante el Acto Legislativo 03 del 2011. Con este, se pretendió limitar el alcance de los fallos judiciales de las altas cortes en procura de mantener una disciplina fiscal adecuada que evite poner en riesgo la estabilidad macroeconómica del país.

En este orden de ideas, para lograr una aproximación al tema, en un primer momento se opera una breve aproximación al problema del desplazamiento forzado interno en Colombia. En un segundo estadio, se aborda el tema específico del concepto de 
Luisa Fernanda García Lozano, Luis Alberto Castellanos Castillo

sostenibilidad fiscal consagrado en el artículo 334 de la Constitución Política, para determinar su incidencia en la reparación administrativa de las víctimas del desplazamiento forzado desde una perspectiva jurídica. Esto se da en cuanto constituye un instrumento que limita el alcance de los desarrollos legales y jurisprudenciales proclives al reconocimiento de los derechos fundamentales de la población desplazada, así como la obligación del Estado de diseñar e implementar programas administrativos de reparación, en consideración a su deber de garantía y no en la obligación de reparación de las víctimas en el marco de procesos judiciales. Finalmente, se aborda un estudio sobre los alcances de la Sentencia T-025 del 2004, mediante la cual se declara el estado de cosas inconstitucional (ECI) en materia de desplazamiento forzado, y también se aborda, por último, el asunto del activismo de la Corte Constitucional en la protección de los derechos fundamentales de la población más vulnerable.

Este artículo es un producto de investigación parcial, pues el desplazamiento aún pervive en el país y continuará extendiéndose en el tiempo mientras subsistan las condiciones políticas, sociales y económicas que constituyen las causas de esta crisis humanitaria. Es de señalar que el período de tiempo que se tuvo en cuenta para desarrollar esta investigación se enmarca entre el 2004, por ser este el año en que se produjo la sentencia hito, y el 2015, cuatro años después de que se estableciera el criterio de sostenibilidad fiscal; esto para poder determinar los efectos de la medida en el tiempo.

\section{Metodología}

Partiendo de un análisis del criterio de sostenibilidad fiscal, incorporado en la Constitución mediante el Acto Legislativo 03 del 2011, se llevó a cabo un proceso de conceptualización del tema, lo que permitió señalar el alcance de este criterio en su carácter limitante de la reparación administrativa de las víctimas del desplazamiento forzado. Ello, con el propósito de determinar si, efectivamente en la práctica, incide en la independencia de las altas cortes al momento de proferir sus fallos. Para abordar esta primera etapa del proyecto de investigación, se acudió al método deductivo, derivado a su vez del método de la lógica y la argumentación jurídica, pues permite partir de un contexto amplio — como es el del desplazamiento forzado — para arribar finalmente a un aspecto particular, el de la 
reparación administrativa, en tanto este método "[...] implica sistematizar conocimiento y establecer inferencias que se aplican a varias situaciones y casos pertenecientes a un conjunto. Posibilita abordar lo desconocido a partir de lo conocido, concluir desde principios generales, consistentes y de gran fuerza lógica” (Villabella, 2015, p. 938).

En un segundo momento, se acudió al análisis jurisprudencial, en el contexto del activismo de la Corte Constitucional y, más precisamente, en el marco de la declaratoria del ECI respecto del desplazamiento forzado con miras a determinar el alcance real y simbólico que dicha declaratoria representaba.

Teniendo en cuenta los derechos de la población desplazada — en el marco de la reparación administrativa a las víctimas de este flagelo-, el activismo de la Corte Constitucional y el criterio se sostenibilidad fiscal, este artículo expone una reflexión que surge de un proyecto de investigación a través del cual se formula un análisis de los componentes de una problemática que ha perdurado en Colombia, con serías incidencias en la construcción social, económica y cultural del país. Partiendo de estos presupuestos, el presente texto tiene como objetivo analizar conceptualmente los aspectos jurídicos de la reparación administrativa y la garantía de los derechos fundamentales de la población desplazada, considerando los elementos constitucionales derivados del activismo judicial de la Corte Constitucional. Todo ello se desarrolla teniendo como referente este interrogante: ¿̇de qué manera la sostenibilidad fiscal constituye una limitante al derecho fundamental a la reparación administrativa de las víctimas del desplazamiento forzado?

\section{La calidad de víctima de desplazamiento forzado}

En este capítulo, se plantea un análisis respecto del estatus legal que tanto la normatividad nacional como internacional han otorgado a las víctimas del desplazamiento forzado en Colombia. Cabe aclarar que, además de la definición y el reconocimiento de la condición de víctima de desplazamiento forzado en los tratados internacionales suscritos por Colombia y de la normatividad interna, la jurisprudencia de la Corte Constitucional ha garantizado la protección de los derechos fundamentales, al formular importantes aportes conceptuales que arrojan mayor claridad y acercamiento al ejercicio de la protección que demanda la población en condición de desplazamiento. 
Luisa Fernanda García Lozano, Luis Alberto Castellanos Castillo

La condición de víctima del conflicto armado, en general, y del desplazamiento, en particular, obedece en gran medida a las circunstancias en que se presentan situaciones de modificación de las condiciones de vida de las personas, normalmente ligadas a la alteración del orden público en las distintas regiones del país, como consecuencia de las acciones de violencia generalizada provocada por diversos agentes armados. En lo que respecta a la categoría de víctima de desplazamiento forzado,

[...] los ataques de los grupos armados, la violencia indiscriminada o la mera presencia de los grupos armados provocan el desplazamiento forzado. El desplazamiento reactivo se produce tras un ataque directo de los grupos armados a la población civil, mientras que el desplazamiento preventivo sucede para evitar una posible victimización futura. [...] la población desplazada es víctima en unas proporciones aterradoras de los ataques de los grupos armados y un alto porcentaje de los hogares se desplaza de manera reactiva. Ello implica que la población desplazada tiene una doble condición de víctima. Por un lado, es víctima de crímenes de lesa humanidad y, por otro lado, es una población en condición de desplazamiento. Los principales detonantes del desplazamiento son las amenazas $(54,5 \%)$, la violencia indiscriminada $(39,1 \%)$, las confrontaciones armadas (36\%), los homicidios $(34,5 \%)$, las órdenes de desalojo (29,6 \%) y las masacres (21,1 \%). (Ibáńez, 2008, p. 14)

Para comprender los efectos que se desprenden del desplazamiento forzado en el país, es necesario aludir al carácter endémico que esta situación ha representado a lo largo de la historia colombiana. Especialmente, se considera que, como consecuencia del conflicto armado, se ha producido una victimización generalizada de la población civil que, durante el período transcurrido entre 1985 y 2013 se produjo la lamentable cifra de 220000 personas muertas, de las cuales un $81,5 \%$ corresponde a población civil y un $18,5 \%$, a combatientes. Estos datos permiten señalar que una de cada tres muertes en Colombia es causada por el conflicto armado (Arias, Camacho, Ibañez, Mejía, y Rodríguez, 2014, p. 25).

Resulta importante indicar que las causas del desplazamiento forzado se han apreciado como concurrentes o independientes, según el elemento que las causa; se destacan entre 
estas los desastres naturales, el desarrollo de megaproyectos o proyectos a gran escala y, en particular, la violencia en sus diversas dimensiones. En el caso colombiano, se evidencia una degradación del conflicto armado interno que ha afectado a la nación por más de medio siglo, según lo que señala Ibarra: "Todas estas causas generan una categorización respecto de quienes lo padecen, y es el de personas desplazadas forzadamente, que son sujetos de protección de acuerdo con el marco legal aplicable de cada Estado, y en observancia de los principios rectores de los desplazamientos internos" (2016, p. 49), de donde se desprende que

[...] a los efectos de estos principios, se entiende por desplazados internos las personas o grupos de personas que se han visto forzadas u obligadas a escapar o huir de su hogar o de su lugar de residencia habitual, en particular como resultado o para evitar los efectos de un conflicto armado, de situaciones de violencia generalizada, de violaciones de los derechos humanos o de catástrofes naturales o provocadas por el ser humano, y que no han cruzado una frontera estatal internacionalmente reconocida. (Comité Internacional de la Cruz Roja, 1998)

Así, puede señalarse, respecto de los principios rectores, que estos se recogen en treinta 30 postulados que abarcan la formulación de un conjunto de principios generales (sección I), principios relativos a la protección contra los desplazamientos (sección II), principios relativos a la protección durante el desplazamiento (sección III), principios relativos a la asistencia humanitaria (sección IV) y finalmente, principios relativos al regreso, el reasentamiento y la reintegración (sección V) (Comité Internacional de la Cruz Roja, 1998).

También la legislación nacional se preocupó por definir la condición del desplazado forzado. Así se plasmó en la Ley 387 de 1997, por la cual se adoptan medidas para la prevención del desplazamiento forzado; la atención, protección, consolidación y estabilización socioeconómica de los desplazados internos por la violencia en la República de Colombia, que, al respecto, señala:

Artículo $1 .^{\circ}$. Del desplazado. Es desplazado toda persona que se ha visto forzada a migrar dentro del territorio nacional abandonando su localidad de residencia o actividades económicas habituales, porque su vida, su integridad 
Luisa Fernanda García Lozano, Luis Alberto Castellanos Castillo

física, su seguridad o libertad personales han sido vulneradas o se encuentran directamente amenazadas con ocasión de cualquiera de las siguientes situaciones:

Conflicto armado interno; disturbios y tensiones interiores, violencia generalizada, violaciones masivas de los derechos humanos, infracciones al derecho internacional humanitario u otras circunstancias emanadas de las situaciones anteriores que puedan alterar drásticamente el orden público.

Parágrafo. El Gobierno Nacional reglamentará lo que se entiende por desplazado.

Asimismo, la ley más reciente encaminada al reconocimiento de los derechos y la protección de las víctimas de la violencia en Colombia, la Ley 1448 del 2011, más conocida como Ley de víctimas y restitución de tierras, reglamentada por los decretos nacionales 4800 del 2011 y 3011 del 2013, en su artículo 60, parágrafo 2. ${ }^{\circ}$, también brinda una definición de lo que se entiende por víctima de desplazamiento forzado:

Parágrafo $2 .^{\circ}$. Para los efectos de la presente ley, se entenderá que es víctima del desplazamiento forzado toda persona que se ha visto forzada a migrar dentro del territorio nacional, abandonando su localidad de residencia o actividades económicas habituales, porque su vida, si integridad física, su seguridad o libertad personales han sido vulneradas o se encuentran directamente amenazadas, con ocasión de las violaciones a las que se refiere el artículo 3. de la presente ley.

Por lo que se refiere a la Corte Constitucional, en algunos de sus más destacados fallos ha señalado que el desplazamiento forzado puede apreciarse como "un problema de humanidad que debe ser afrontado solidariamente por todas las personas, principiando, como es lógico, por los funcionarios del Estado" (C. C., Sentencia T-227-1997, Colomb.). También señaló en otro pronunciamiento "un verdadero estado de emergencia social", "una tragedia nacional, que afecta los destinos de innumerables colombianos y que marcará el futuro del país durante las próximas décadas" y "un serio peligro para la sociedad política colombiana” (C. C., Sentencia SU-1150 del 2000, Colomb.), además 
de añadir que también se constituye en un estado de cosas inconstitucional que "contraría la racionalidad implícita del constitucionalismo" al generar una pugna entre la "pretensión de organización política y la prolífica declaración de valores, principios y derechos contenidas en el Texto Fundamental y la diaria y trágica constatación de la exclusión de ese acuerdo de millones de colombianos" (C. C., Sentencia T-215, Colom.).

Tras realizar un detallado estudio sobre las condiciones que deben afrontar las víctimas del desplazamiento forzado, la Corte Constitucional ha sido reiterativa, desde la Sentencia T-025 de 2004, sobre la urgente necesidad de brindar a la población en condición de desplazamiento todos los medios necesarios para que, mediante la implementación de acciones públicas, pueda ofrecerse la ayuda adecuada y necesaria para que estas personas puedan superar la situación de vulnerabilidad manifiesta en que se encuentran y lograr el goce efectivo de sus derechos.

De la constatación de la violación de los derechos humanos con ocasión del desplazamiento forzado, como lo señala Bolívar (2012), uno de los antecedentes más cercanos se relaciona con el reconocimiento y la garantía de la reparación a las víctimas de la violencia en Colombia. Se evidenció que, desde el marco normativo del derecho a la reparación y su alcance desde las experiencias internacionales a través de programas administrativos de reparación, en un estudio comparado como también sistemático de las experiencias internacionales del cual se extrajeron algunos criterios mínimos que deben ser tenidos en cuenta al momento de diseñar estos programas en un escenario nacional. En el 2005, con ocasión del proceso de desarme y desmovilización de los grupos paramilitares, el Congreso de la República expidió la Ley 975 del 2005, mediante la cual se buscó la manera de reincorporar a los miembros de los grupos armados al margen de la ley, buscando que contribuyeran de manera efectiva a la consecución de la paz. Se pretendió, además, que tanto víctimas como victimarios lograran acceder a la justicia, permitiendo que las primeras alcanzaran, mediante la implementación de medidas especiales, la reparación tanto en sede judicial como administrativa.

Sin embargo, los objetivos inicialmente propuestos mediante esta ley —cobijados por el Decreto 1290 del 2008 (derogado por el art. 297 del Decreto Nacional 4800 del 2011), por el cual se crea el Programa de Reparación Individual por vía Administrativa para las Víctimas de los Grupos Armados Organizados al Margen de la Ley_ no fueron 
Luisa Fernanda García Lozano, Luis Alberto Castellanos Castillo

contundentes en su teleología. Esto se debió a que obstaculizaron en gran medida las posibilidades reales de las víctimas de alcanzar una reparación adecuada, pues tal decreto imponía limitaciones a las víctimas para acceder a la reparación, por lo que se precisa entonces resaltar "el alcance limitado de las medidas otorgadas, la exclusión de las víctimas colectivas y de las víctimas del Estado o de sus agentes y la confusión entre medidas de ayuda humanitaria, política social y la reparación” (Bolívar, 2012, p. 4).

Entendidas las medidas de reparación administrativa dentro de un contexto de transición o posconflicto, estas ofrecen un alcance más amplio que las simples reparaciones judiciales, pues su campo de cobertura se extiende a situaciones de violación masiva de derechos humanos, ya que, a diferencia de la reparación en sede judicial, la administrativa establece una cobertura mayor que se fundamenta en tarifas fijadas que consideran criterios auxiliares, entre los cuales se incluyen el tipo de crimen, el daño sufrido y la condición de la víctima. Esta información permite conformar las bases de datos que tienen en cuenta las condiciones socioeconómicas de las víctimas, la vulneración sufrida, los daños y perjuicios ocasionados, su estructura familiar y los vínculos de dependencia afectivos y emocionales que resultaron vulnerados con el desplazamiento forzado (Bolívar, 2012).

En este mismo contexto, más recientemente se expidió la Ley 1448 del 2011, encaminada a la atención, asistencia y reparación integral de las víctimas del conflicto armado interno. Esta permitió la adopción de medidas que deben adelantar las instituciones del Estado con el propósito de brindar, al amplio universo de víctimas de la violencia en el país, la reparación integral, en procura de superar el estado de marginalidad que históricamente han padecido (García Londoño, 2014, p. 4).

\section{La reparación administrativa como derecho fundamental}

En diferentes fallos, la Corte Constitucional ha puesto de presente que a las víctimas de la violencia en Colombia les asiste el derecho a obtener reparación integral, entendida esta más allá de la simple compensación económica en los procesos adelantados contra los responsables del daño; y sus efectos se extienden a todos los dańos y perjuicios sufridos por la víctima tanto a título individual como comunitario. En cuanto a la reparación 
individual, esta comprendería: 1) la restitutio in integrum, o reposición de la situación a su estado original; 2) la indemnización o reparación por equivalencia en dinero y 3) la satisfacción o reparación moral (C.C., Sentencia T-458-2010, Colom.).

Además, reiterando lo ya citado, el Tribunal Constitucional ha señalado que tanto las víctimas individuales como las colectivas de delitos, en general, así como quienes hayan sufrido graves violaciones de los derechos humanos y desplazamiento forzado, en particular, cuentan con vías legales que les permiten obtener el derecho a la reparación integral. Por ello, se estableció en el ordenamiento jurídico un camino de reparación por vía judicial y otro por vía administrativa. Es importante, entonces, marcar una pequeña diferencia entre las características que presentan estos dos mecanismos de reparación (C. C., Sentencia T-458-2010, Colom.).

En primer lugar, es de aclarar que la reparación en sede judicial se refiere al otorgamiento de justicia a las personas consideradas de manera individual, partiendo de la investigación hasta culminar con la sanción de los responsables en cada caso particularmente analizado. Ello incorpora, además, la verdad en cuanto al esclarecimiento del delito y las medidas reparatorias de restitución, compensación y rehabilitación de la víctima, acciones todas estas desplegadas en el marco de la búsqueda de una reparación plena del daño antijurídico padecido por la víctima (C. C., Sentencia SU-254-2013, Colom.).

Por otra parte, la reparación por vía administrativa cuenta con un enfoque comparativo, debido a lo siguiente: 1) se trata de reparaciones con carácter masivo; 2) al pretender una reparación integral, que se compone de variados elementos, ella se fundamenta básicamente en el principio de equidad, en la medida en que permite una reparación plena del daño, ante la imposibilidad de determinar con exactitud su dimensión, proporción o cuantía y 3) se constituye en una vía expedita que facilita el acceso de las víctimas a la reparación, en la medida en que comprende procesos rápidos, económicos y flexibles en cuestiones probatorias (C. C., Sentencia SU-254-201, Colom.).

En el caso específico de la reparación por vía legal-administrativa, esta se logra mediante el cumplimiento de requisitos legales o administrativos que permitan la reparación del daño, ajustado a tarifas preestablecidas y con exoneración de la necesidad de identificar al autor material del delito. En cuanto a la reparación judicial, esta se presenta a partir de la 
reclamación ante un juez: se adelantan las etapas de un proceso y se obtiene una providencia favorable en la que se identifica al responsable del daño ocasionado (M. López, 2014).

En consecuencia, las víctimas pueden acudir tanto a la reparación por vía administrativa como por vía judicial; así, uno y otro mecanismo revisten características particulares, pues, como lo señala Lopez (2014) citando a Uprimny, Sánchez y Bolívar (2010),

La reparación por vía administrativa permite reparar en contextos en los que no es posible identificar la magnitud plena del daño y sus responsables, de manera que implica menores cargas probatorias para las víctimas. Además, ofrece mayor cobertura y facilita el aprovechamiento eficiente de los recursos con la entrega de paquetes uniformes de beneficios. A todo lo anterior, debe sumarse que los remedios pueden llegar más pronto y ser más oportunos que los ofrecidos después de un largo proceso judicial. Sin embargo, se puede ignorar que el DEFo causa impactos diferentes en sus víctimas al reparar bajo un sistema de tarifas. Asimismo, al no hacer mucho énfasis en la identificación de los responsables, pueden quedar abiertas las puertas hacia la impunidad y la violación de los derechos a la verdad y la justicia. (p. 129)

Por otra parte, el Estado tampoco puede sustraerse de la obligación de indemnizar a las víctimas de la violencia, pues, tal como lo establece el artículo $10 .^{\circ}$ de la Ley 1448 del 2011, impera un principio de subsidiariedad, que seńala:

Artículo 10. Condenas en subsidiariedad. Las condenas judiciales que ordenen al Estado reparar económicamente y de forma subsidiaria a una víctima debido a la insolvencia, imposibilidad de pago o falta de recursos o bienes del victimario condenado o del grupo armado organizado al margen de la ley al cual este perteneció, no implican reconocimiento ni podrán presumirse o interpretarse como reconocimiento de la responsabilidad del Estado o de sus agentes.

En los procesos penales en los que sea condenado el victimario, si el Estado debe concurrir subsidiariamente a indemnizar a la víctima, el pago que este deberá reconocer se limitará al monto establecido en el reglamento correspondiente para la indemnización individual por vía administrativa de que trata la presente 
ley en el artículo 132, sin perjuicio de la obligación en cabeza del victimario de reconocer la totalidad de la indemnización o reparación decretada dentro del proceso judicial.

Ahora bien, por constituir la reparación integral un derecho fundamental, en aras de permitir su cumplimiento, procede su exigibilidad mediante la acción de tutela o la acción de grupo ante las instituciones estatales que denieguen su reconocimiento o su efectividad. Sin embargo, es indispensable tener en cuenta que la manera en que el Estado ha venido cumpliendo, en mayor o menor medida, con las exigencias judiciales que amparan y reconocen derechos fundamentales — en el caso particular, a la población desplazada — se encuentra supeditado a la disponibilidad de recursos económicos, pues no se puede dejar de lado el vasto número de víctimas provocadas por el conflicto armado que, según las cifras oficiales presentadas por la Unidad de Víctimas, ascienden a 8208564 , discriminadas como lo muestra la tabla 1 .

Tabla 1. Número de víctimas provocadas por el conflicto armado (desagregado por hecho)

\begin{tabular}{lr}
\multicolumn{1}{c}{ Hecho } & Personas \\
\hline Abandono o despojo forzado de tierras & 5432 \\
\hline Acto terrorista/atentados/combates/ hostigamientos & 96278 \\
\hline Amenaza & 363374 \\
\hline Delitos contra la libertad y la integridad sexual & 22915 \\
\hline Desaparición forzada & 167809 \\
\hline Desplazamiento & 7265072 \\
\hline Homicidio & 990410 \\
\hline Minas antipersonal/munición sin explotar/artefacto explosivo & 11140 \\
\hline Perdida de bienes muebles o inmuebles & 111656 \\
\hline Secuestro & 36162 \\
\hline Sin información & 81 \\
\hline Tortura & 10639 \\
\hline Vinculación de niños, niñas y adolescentes & 8382 \\
\hline
\end{tabular}

Fuente: cifras de la Unidad de Víctimas (consulta: 20 de septiembre del 2017). 
La complejidad de la situación en la que se ve inmerso un país como Colombia, con el fin de culminar el conflicto y sus consecuencias, establece que derechos fundamentales que obedecen a la búsqueda de la garantía de derechos y de superar la desigualdad en marcos objetivos despierten esperanzas, pero al mismo tiempo, se vean limitados por aspectos económicos y sociales que vuelven improbable su concreción.

\section{Sostenibilidad fiscal como límite de la reparación administrativa}

Frente a este número tan amplio de víctimas, resulta pertinente plantearse una reflexión en torno a la manera en que presupuestalmente se pueda cumplir con el reconocimiento, principalmente, de medidas indemnizatorias a gran escala. Sin llegar a una elaboración sofisticada de cálculos matemáticos, cabe plantearse cuestionamientos en torno a la manera en que el Estado pueda establecer estrategias macroeconómicas que, desde la perspectiva de sostenibilidad fiscal, permitan, por un lado, cumplir con las garantías de reconocimiento del derecho efectivo a la reparación administrativa de las víctimas y, por el otro, conservar la estabilidad de las finanzas públicas.

Para entrar en una disertación seria en este tema, es necesario emprender una aproximación conceptual a lo que se entiende por sostenibilidad fiscal y la manera como el reconocimiento de la reparación puede afectar las finanzas públicas, sin olvidar que

[...] las reparaciones son una expresión material del reconocimiento debido a aquellos sujetos cuyos derechos fundamentales han sido violados. La reparación parte del reconocimiento de lo que pasó, de las consecuencias que esto ocasionó en la vida de las víctimas y de la responsabilidad — jurídica, moral y política - que le cabe al Estado en las violaciones a los derechos humanos. La reparación expresa la decisión del Estado de acoger en la comunidad política a aquellas personas que antes fueron excluidas, perseguidas y victimizadas, y el compromiso de que lo que pasó no vuelva a ocurrir. (C. Díaz, 2010, p. 7)

Una aproximación al concepto de sostenibilidad fiscal, según lo exponen Rosas, Plazas y Bernal, permite comprender que 
[...] la sostenibilidad fiscal se refiere a la consistencia de los planes de gasto e impuestos de largo plazo con los objetivos de la política monetaria y la acumulación de capital en la economía. Una situación fiscal es sostenible cuando garantiza de manera continua la capacidad de pago de las obligaciones contraídas por el gobierno. Más específicamente, para establecer la sostenibilidad de la posición fiscal debemos responder al interrogante si los ingresos del sector público son suficientes para financiar los programas de gasto o para sostener una determinada dinámica de gasto público, sin comprometer otras metas importantes de la política económica, principalmente la estabilidad de precios y la acumulación de capital. (2013, p. 23)

Así, pues, vale reseñar que la garantía en el reconocimiento de los derechos a la población desplazada, principalmente en el aspecto de la reparación administrativa al vincular directamente las finanzas públicas, demanda por parte del gobierno nacional el desarrollo de políticas públicas en el marco de un ejercicio de estructuración económica de la sostenibilidad fiscal. Mediante este, sería posible morigerar la tensión que pueda darse entre el cumplimiento efectivo del derecho a la reparación administrativa, por un lado, y la preservación de la sostenibilidad fiscal, por el otro. Así también lo ha expresado la Corte Constitucional cuando señala que el criterio de sostenibilidad fiscal se encamina a disciplinar las finanzas públicas permitiendo que la proyección de su desarrollo futuro minimice el déficit fiscal mediante la limitación de la diferencia entre los ingresos nacionales y el gasto público (C. C., Sentencia C-288-2012, Colom.).

Es importante referir que el criterio de sostenibilidad fiscal puede llegar a condicionar el alcance efectivo de los derechos de la población desplazada, pues incorpora el denominado incidente de impacto fiscal, introducido en la Constitución mediante el Acto Legislativo 03 del 2011, promulgado el $1 .^{\circ}$ de julio de ese ańo y que modificó los artículos 334, 339 y 346 del cuerpo constitucional. En efecto, el artículo 334 señala en uno de sus apartes:

El procurador general de la nación o uno de los ministros del gobierno, una vez proferida la sentencia por cualquiera de las máximas corporaciones judiciales, podrán solicitar la apertura de un incidente de impacto fiscal, cuyo trámite será obligatorio. Se oirán las explicaciones de los proponentes sobre 
Luisa Fernanda García Lozano, Luis Alberto Castellanos Castillo

las consecuencias de la sentencia en las finanzas públicas, así como el plan concreto para su cumplimiento y se decidirá si procede modular, modificar o diferir los efectos de la misma, con el objeto de evitar alteraciones serias de la sostenibilidad fiscal. En ningún caso se afectará el núcleo esencial de los derechos fundamentales.

Parágrafo. Al interpretar el presente artículo, bajo ninguna circunstancia, autoridad alguna de naturaleza administrativa, legislativa o judicial, podrá invocar la sostenibilidad fiscal para menoscabar los derechos fundamentales, restringir su alcance o negar su protección efectiva.

En ese orden de ideas, solo cuatro días después de la reforma constitucional, se promulgó la Ley 1473 del 2011, por medio de la cual se establece una regla fiscal. Como complemento a ella, el Congreso expidió la Ley 1695 del 2013, por medio de la cual se desarrolla el artículo 334 de la Constitución Política y se dictan otras disposiciones; en resumidas cuentas, lo que hizo esta última ley fue reglamentar el incidente de impacto fiscal, lo que, en conjunto con la reforma constitucional, logró complementar un paquete de medidas que permitió al gobierno fijar una disciplina fiscal en el manejo de las finanzas públicas (Gómez, 2015).

Varias posturas han adoptado expertos y académicos en torno a la posible vulneración del Estado Social de Derecho que indujo la incorporación del criterio de sostenibilidad fiscal. Por un lado, existen argumentos que señalan una vulneración de la garantía del reconocimiento y protección de los derechos fundamentales y, por otro lado, se plantean posiciones a favor de esta medida, principalmente por parte de los defensores de la estabilidad macroeconómica como una necesidad de primer orden para el Estado.

En defensa de la primera postura, se encuentra Romero, quien argumenta que

[...] el artículo 2 de la Constitución política de Colombia establece los fines del Estado, entre los cuales destaca: garantizar la efectividad de los principios, derechos y deberes consagrados en la Constitución, tarea que implica responsabilidades por parte de las autoridades de la República encaminadas a proteger a todas las personas en su vida, honra, bienes, creencias, y demás 
derechos y libertades, y para asegurar el cumplimiento de los deberes sociales del Estado y de los particulares. En este sentido, es un deber preferente del Estado la creación y mantenimiento de las condiciones materiales indispensables para garantizar la calidad de vida de los asociados, especialmente en aquellas circunstancias de urgencia, peligro o penuria extrema que amenacen la dignidad de las personas o la protección de sus bienes. (2014, p. 352)

En tal sentido, se hace necesaria la universalización de los derechos sociales, como lo afirma el Pacto Internacional de Derechos Económicos, Sociales y Culturales (Pidesc), que, dentro de los discursos de los derechos humanos, se presume integrado, pero que, en el caso colombiano, entra en una contradicción, debido a las serias limitaciones estructurales que se presentan. Esto obedece a que el Estado se ha limitado a ser un espectador más en la definición de lo económico, con una limitada acción regulatoria cuyo aporte más significativo es la ejecución de programas asistencialistas o el desarrollo de normas constitucionales regresivas, de lo que se deriva un desarrollo limitado que dificulta notoriamente el logro de unos DESC con carácter de permanencia (Romero, 2014). Concluye este autor reafirmando que

[...] los derechos económicos, sociales y culturales han quedado reducidos a un simple vinculo de responsabilidad política que delega nuevamente en el legislador la eficacia de los derechos mencionados y condiciona la materialización de los mismos a la disponibilidad de recursos para hacerlos efectivos. En este orden de ideas, la norma constitucional retornó al modelo liberal del Estado de Derecho y fue reducida a una función simbólica, es decir, a un documento programático sin poder vinculante. (Romero, 2014, p. 364)

También debe considerarse que la falta de reconocimiento y garantía de los derechos de la población desplazada constituye un atentado contra el ejercicio de los derechos económicos, sociales y culturales, tal como lo señala la declaración de la Comisión interamericana de Derechos Humanos de la Organización de Estados Americanos:

El fenómeno de la violencia generalizada analizado detenidamente por la Comisión en otros Capítulos del presente Informe, aunado a la situación de los miles de colombianos que viven desplazados de sus hogares, repercute 
Luisa Fernanda García Lozano, Luis Alberto Castellanos Castillo

negativamente en la vigencia real de los derechos económicos, sociales y culturales. (Organización de Estados Americanos, 1999)

Se trata de una condición que plantea un escenario de posible confrontación entre la exigencia de la sostenibilidad fiscal y la justiciabililidad de los derechos sociales. Frente a esta posible contraposición de intereses, puede indicarse que tradicionalmente el camino hacia la exigibilidad de los derechos sociales se ha efectuado por la vía política, más que por la vía judicial. En consecuencia, cuando el gobierno se compromete con el diseño y ejecución de acciones públicas, los ciudadanos cuentan con la opción de presionar su cumplimiento a través de un control del poder político. No obstante, al respecto existen dos posturas: 1) la primera sostiene la vaguedad conceptual y la falta de precisión normativa con que se redactan las disposiciones constitucionales y 2) la postura de juristas y jueces que señalan que los derechos económicos, sociales y culturales (DESC) no tienen el verdadero carácter de derechos; por tanto, carecen de exigibilidad o reclamación judicial (G. López, 2012).

En el caso de Colombia, tras la incorporación del criterio de sostenibilidad fiscal, como lo expone López citando a Noguera (2007), "el principal problema para el desarrollo de los derechos sociales es la justiciabilidad, y no su validez" (2012, p. 25). En consecuencia, el cumplimiento de los DESC está supeditado a la formulación de propuestas públicas claras que permitan a la significativa masa de ciudadanos en condiciones de exclusión acceder, entre otros, a servicios de salud, educación, seguridad social y vivienda. No obstante, para lograr ese propósito, debe considerarse que, a diferencia de los derechos de primera generación (también denominados políticos y civiles), los que demandaban una obligación negativa o de dejar de hacer, consistente en la abstención del ejercicio de potestades que limitaran tales derechos, los DESC — o derechos de segunda generación— demandan una obligación positiva o de hacer por parte del Estado. Es entonces, en este punto nodal, en donde la necesidad de limitar las decisiones de los jueces implica de manera directa restricciones presupuestales a la garantía de los derechos sociales.

Sin embargo, desde otra perspectiva, se plantean posturas contrarias a las que precisan la sostenibilidad fiscal como una limitante al reconocimiento de los DESC y, en el caso de este artículo, de las víctimas del desplazamiento forzado. Así, por ejemplo, economistas de la talla de Salomón Kalmanovitz son claros al referir que, cuando se constitucionaliza una política pública, se modifica su esencia al introducir rigideces que, más que favorecer 
afectan el desarrollo del país, pues se parte de la idea de que un texto legal generará una mejora sustancial en las condiciones reales, sin considerar que para obtener resultados verdaderamente significativos, lo que se demanda es el compromiso del gobierno en asuntos macroeconómicos (Kalmanovitz, 2011).

Desde su visión, Kalmanovitz también señala que bien puede considerarse innecesaria la reforma constitucional, pues hubiese sido suficiente la expedición de una ley que permitiera al ejecutivo controlar las decisiones judiciales en tanto estas puedan afectar la sostenibilidad fiscal. En efecto, para el economista, lo realmente interesante es que la sostenibilidad fiscal tiene como objetivo restringir las erogaciones derivadas del incumplimiento de los mandatos del gasto social que representan derechos consagrados en la Constitución y, por lo tanto, cuando las demandas y tutelas en contra del Estado prosperan pueden desencadenar un gasto no presupuestado que afectará la situación fiscal del país.

Un remedio a esta tensión sugiere el economista: que los llamados a desempeñar un rol determinante en este contexto son los jueces, ya que, al momento de fallar, deben considerar el impacto de sus providencias, atendiendo a que el gasto surge de la representación popular y, en este sentido, el poder judicial debe limitar una eventual afectación macroeconómica, máxime cuando es una labor que escapa a la órbita de sus funciones. Por lo tanto, después de disertar sobre la incidencia de la sostenibilidad fiscal y la garantía de los DESC, para López, la conclusión es que

[...] este "experimento constitucional colombiano" no tiene otro propósito que limitar el gasto de los derechos sociales realizados por los jueces, creando un nuevo principio denominado "principio de sostenibilidad fiscal", a pesar de que la normatividad prevé mecanismos para controlar el gasto público. [...] En el caso de que la Corte Constitucional deba proteger un derecho fundamental y deba ordenar un gasto para su protección, el incidente de impacto fiscal no será el medio idóneo para evitar la orden toda vez que existen derechos fundamentales que deben ser protegidos y primará su amparo, pues como la misma norma lo expresa, no se podrán afectar los derechos de las personas afectadas. Así las cosas, este principio de sostenibilidad fiscal no parece ser el mecanismo idóneo para evitar que se siga comprometiendo el presupuesto 
Luisa Fernanda García Lozano, Luis Alberto Castellanos Castillo

nacional por medio de las decisiones judiciales de las altas cortes en materia de derechos sociales. (2014, pp. 37-38)

Un aspecto que se debe tener presente es que, si bien para algunos académicos y también para algunos juristas, la sostenibilidad fiscal podría representar una regresión en el reconocimiento de los derechos sociales de los ciudadanos - entre los que se cuentan las víctimas del desplazamiento forzado-, lo cierto es que la Corte Constitucional se pronunció en la Sentencia C-288 del 2012 con respecto a ese asunto. En su argumentación, señala, entre otras cosas, que, pese a no existir una definición convencional del concepto de sostenibilidad fiscal, le reconoce a este un amplio margen de interpretación. Igualmente, el alto tribunal se refiere a la relación de complementariedad existente entre la cláusula del Estado Social de Derecho y las modalidades constitucionales en que el Estado puede intervenir en la política económica, al conceder al Congreso de la República un amplio margen de configuración legislativa mediante la adopción de mecanismos de carácter económico que permitan salvaguardar y cumplir aquellos fines consagrados en la Constitución (Rosas et al., 2013). Así se aprecia en los fundamentos de la referida sentencia:

Existe, por lo tanto, una plena consonancia entre la definición del ESDD y las modalidades constitucionales de intervención del Estado en la economía. Mientras el primero tiene por objetivo esencial alcanzar la igualdad de oportunidades y la satisfacción, en especial a las personas más vulnerables, de los derechos y garantías necesarios para una ciudadanía material, las segundas están instituidas para conducir al mercado en la consecución de esas finalidades y bajo idéntico criterio de igualdad sustantiva. En otros términos, el principio de ESDD impone a las autoridades estatales unas funciones particulares, las cuales se cumplen también de diversos modos, destacándose la intervención en la economía, que opera como instrumento para el logro de los fines esenciales del aparato estatal. Esto implica, lo que resulta especialmente importante para la presente decisión, que la Constitución y la ley puede establecer, a través de normas jurídicas, otros mecanismos de incidencia del Estado en las relaciones sociales, a condición que están unívocamente dirigidas a la preservación de los fines estatales que define el núcleo dogmático de la Carta (arts. $1 .{ }^{\circ}$ y $2 .^{\circ}$ C. P.). (C. C., Sentencia C-288-2012, Colom.) 
Es desde estos fundamentos dogmáticos como la Corte le reconoce a la sostenibilidad fiscal un criterio meramente instrumental, que permite la consecución progresiva de los objetivos del ESD. En relación con este mismo aspecto, el legislador fue cauteloso al momento de expedir leyes como la denominada Ley de víctimas y restitución de tierras, pues en un contexto de reparación tan amplio, se consideró el impacto que la ejecución de dicha ley provocaría en la hacienda pública; de ahí que en el artículo 9. ${ }^{\circ}$ de ese cuerpo normativo se mencionaran directamente las medidas transicionales que disponen

\begin{abstract}
[...] en el marco de la justicia transicional las autoridades judiciales y administrativas competentes deberán ajustar sus actuaciones al objetivo primordial de conseguir la reconciliación y la paz duradera y estable. Para estos efectos se deberá tener en cuenta la sostenibilidad fiscal, la magnitud de las consecuencias de las violaciones de que trata el artículo $3 .^{\circ}$ de la presente ley, y la naturaleza de las mismas. (Ley 1448 del 2010, art. 9, Colom.)
\end{abstract}

La Ley 1448 del 2011 resulta de especial importancia, pues otorga al gobierno la posibilidad de ampliar las funciones a las entidades tanto del nivel central como territorial para lograr la mayor cobertura posible en cuanto a la atención a las víctimas. En consecuencia, también se da vida a la Unidad para la Atención y la Reparación Integral a las Víctimas (Uariv) que agrupa, además de las funciones, las competencias que en su momento se establecieron en las leyes 387 de 1997, 418 de 1997 y 975 del 2005, así como en el Decreto 1290 del 2008 y demás normas encaminadas a brindar atención a las víctimas del desplazamiento. La Uariv asumió las competencias que tenían la Agencia Presidencial para la Acción Social y la Cooperación Internacional como también la Comisión Nacional de Reparación y Reconciliación. No obstante, frente a la difícil tarea de ofrecer una cobertura integral a todas las víctimas en un mismo momento, el gobierno nacional se vio abocado a expedir el Decreto 1377 del 2014. Este reglamentó la entrega de ayudas humanitarias y reparaciones administrativas con sustento en criterios de priorización, que tienen en cuenta, principalmente, los procesos de retorno, ubicación e indemnización individual administrativa (C. C., Sentencia T-130-2016, Colom.). A su vez, el artículo 19 de la Ley 1448 del 2011 está dedicado a limitar la puesta en marcha de esa misma ley, a fin de lograr la concreción del principio de progresividad en un marco de sostenibilidad fiscal: 
Luisa Fernanda García Lozano, Luis Alberto Castellanos Castillo

El desarrollo de las medidas a que se refiere la presente ley, deberá hacerse en tal forma que asegure la sostenibilidad fiscal con el fin de darles, en conjunto, continuidad y progresividad, a efectos de garantizar su viabilidad y efectivo cumplimiento.

En definitiva, la sostenibilidad fiscal puede interpretarse como restrictiva tanto del alcance como del reconocimiento de los derechos de la población en condición de desplazamiento forzado. Pero no es menos importante reconocer que, dado el amplio número de personas víctimas de esta condición, en la medida en que el gobierno nacional carezca de un modelo macroeconómico eficiente y sustentable en el mediano y largo plazo, las entidades del Estado enfrentarán una misión titánica para cumplir las demandas de amparo por parte de la rama judicial en su calidad de juez constitucional, que propende por la protección de los derechos fundamentales de grupos en estado de vulneración y marginalidad.

\section{Análisis de la sentencia T-025 del 2004 y el activismo de la Corte Constitucional}

La particularidad de la Sentencia T-025 del 2004 produce un cambio sustancial en la forma de entender y conceptuar el derecho, en virtud de la transformación de dos supuestos de la Corte: el primero es la concreción de los fallos de los tribunales. A partir de la creación de la Corte Constitucional, la concepción de garantía de los derechos se centró en que estos se reconocieran en los fallos judiciales, principalmente los relacionados con aspectos económicos, por cuanto la Corte ordenaba su ejecución, pero existía la limitación para concretarla debido al presupuesto de la entidad o a la falta de voluntad política. La concepción de la eficacia simbólica se enraizó en la necesidad de reconocimiento; por tanto, llevar a la práctica la decisión no era un asunto que entrara en la agenda. En este sentido, se cambió el concepto de garantía por eficacia. El segundo supuesto es el papel de la Corte en la materialización de los fallos, ya que cambia los elementos de la competencia y somete a las instituciones a rendición de cuentas.

Así, se establece un nuevo nivel en la búsqueda de concreción de los derechos, aspecto que se ha denominado activismo judicial. Las consecuencias de las decisiones y las funciones 
del Estado se configuran como parte de la discusión y demuestran el contenido político del derecho y sus consecuencias, además de evidenciar las principales falencias en la composición del Estado a través de sus instituciones.

La sentencia T-025 del 2004 constituye la sentencia hito en cuanto al desplazamiento forzado. A través de ella, la Corte Constitucional es clara cuando afirma que, entre los múltiples factores que inciden en la implementación de las medidas de atención a la población desplazada, sobresale la falta de recursos asignados por el gobierno nacional, lo que se extiende a las entidades territoriales que han seguido este mismo patrón de austeridad. Ello redunda en que las entidades que conforman el Sistema Nacional de Atención Integral a la Población Desplazada (SNAIPD) se encuentren limitadas para cumplir las directrices en cuanto a lograr la concreción de la atención (C. C., Sentencia T-025-2004, Colom.).

Como lo expone García Lozano (2014), en este escenario, teniendo como sustento fundamentos ontológicos y jurídicos, la Corte Constitucional planteó la posibilidad de tomar esta clase de decisiones siguiendo lo preceptuado en el preámbulo de la Constitución, donde se establece que Colombia asume la formula política del Estado Social de Derecho, lo que se revierte en la necesidad de un engranaje armónico entre las distintas ramas del Poder Público, en aras de velar por el efectivo cumplimiento de las acciones que le han sido encomendadas. De ahí que, al conectar este principio con el artículo $1 .^{\circ}$ de la Constitución, referente a la protección de los derechos fundamentales, se amplía su campo de acción a los derechos económicos, sociales y culturales, entendidos como la concreción del principio de la dignidad humana y de la solidaridad.

A través de la Sentencia T-025 del 2004, la Corte expone que, en el asunto del desplazamiento, se dan los presupuestos necesarios para declarar el estado de cosas inconstitucional. Así, pueden distinguirse los elementos que confirman esta declaratoria:

1. El legislador ha reconocido de manera expresa la gravedad de la situación de vulnerabilidad de derechos que padece la población desplazada, evidencia de ello es la definición de la condición de desplazado, que incluye resaltar la violación masiva de múltiples derechos. 
2. El incremento en el elevado número de acciones de tutela presentadas por los desplazados requiriendo la protección de sus derechos y en procura de obtener las ayudas adecuadas.

3. La acumulación de procesos en la presente acción de tutela, es el reflejo de la existencia de un estado de cosas inconstitucional y advierten se evidencia una vulneración generalizada de los derechos de la población desplazada, que se presenta en múltiples lugares del territorio nacional, y que, además, ha existido una omisión por parte de las autoridades para atender tales requerimientos.

4. Existe concurrencia de imputabilidad en cuanto a la responsabilidad de las autoridades en desatender la situación de desplazamiento.

5. Existencia de serias fallas estructurales: 1) incongruencia entre lo que disponen las normas y los medios para cumplirlas, que no es otra cosa que la falta de recursos en consideración a la evolución del problema, que pone de manifiesto la incapacidad institucional para dar respuesta oportuna, adecuada y eficiente a sus componentes. (C. C., Sentencia T-025-2004, Colom.)

La sentencia se encargó de desarrollar un estudio con base en 108 expedientes de tutela a través de los cuales 1050 núcleos familiares en circunstancias de desplazamiento forzado acudieron ante la jurisdicción, con el fin de que se diera tramite a sus solicitudes. El problema jurídico bajo examen se centró en la falta de atención de las autoridades competentes para prestar la atención humanitaria, entre las que figuran la Red de Solidaridad Social, el Departamento Administrativo de la Presidencia de la República, el Ministerio de Hacienda y Crédito Público, los ministerios de salud y del trabajo y seguridad social (actual Ministerio de Protección Social), el Ministerio de Agricultura, el Ministerio de Educación, el Inurbe, el Incora, el Sena y los organismos territoriales entre municipios y departamentos (García Lozano, 2014).

Uno de los aspectos que más resalta al momento de evaluar el alcance de los programas de atención a la población desplazada tiene que ver con la asignación presupuestal y la capacidad de las entidades estatales encargadas de diseñar, ejecutar y evaluar dichos programas. 
El activismo de la Corte no solo se explica en su rol de garante de la Constitución y en la reiterada y grave violación de derechos. Existen dos elementos adicionales que explican dicho comportamiento:

a. La incapacidad de las entidades públicas y las organizaciones de la sociedad civil (eg.: organismos de control y veedurías ciudadanas) encargadas de demandar rendición de cuentas, incapacidad que se puede explicar en la falta de legitimidad y sanción con las que cuentan dichas entidades u organizaciones. Esta característica facilita el incumplimiento estatal que se evidencia en el caso de la PPAPD.

b. El funcionamiento deficiente del legislador. Al respecto, Landau (2011) argumenta que el sistema de partidos en el país es débil, por tanto, el Congreso no funciona como una entidad coherente y no recoge el interés general sino intereses particulares, lo que implica que los grupos que cuentan con menor poder político van a ver sus intereses afectados e incluso ignorados. (Morales, 2012, p. 62)

También refiere García Lozano (2014) que, con respecto a la insuficiencia de asignación de recursos como causa de las fallas estructurales que hacen nugatoria la garantía de derechos a los desplazados, en su pronunciamiento, la Corte resaltó que corresponde al Estado valerse tanto de los medios legales como de los constitucionales adecuados para corregir las notorias desigualdades sociales, lo que permita superar la exclusión al propiciar espacios de participación de los sectores marginados, débiles y vulnerables de la población, en el circuito económico de interacción social de la nación. Ello debe reflejarse en un mejoramiento progresivo de las condiciones materiales de los sectores más discriminados de la sociedad; para ello, en sus fundamentos jurídicos rememoró que, del artículo 2 . $^{\circ}$ constitucional, se derivan para el Estado dos clases de deberes:

Por una parte, debe adoptar e implementar las políticas, programas o medidas positivas para lograr una igualdad real de condiciones y oportunidades entre los asociados y al hacerlo, dar cumplimiento a sus obligaciones constitucionales de satisfacción progresiva de los derechos económicos, sociales y culturales básicos de la población —en aplicación de lo que la jurisprudencia constitucional ha 
Luisa Fernanda García Lozano, Luis Alberto Castellanos Castillo

\begin{abstract}
denominado "cláusula de erradicación de las injusticias presentes" - . Y, por otra, debe abstenerse de adelantar, promover o ejecutar políticas, programas o medidas ostensiblemente regresivos en materia de derechos económicos, sociales y culturales, que conduzcan clara y directamente a agravar la situación de injusticia, de exclusión o de marginación que se pretende corregir, sin que ello impida avanzar gradual y progresivamente hacia el pleno goce de tales derechos. (C. C., Sentencia T-025-2004, Colom.)
\end{abstract}

Con anterioridad a la expedición de la Sentencia T-025 del 2004, es importante señalar que, antes de este pronunciamiento, el alto tribunal había proferido 17 sentencias relacionadas con el tema del desplazamiento forzado. Un aspecto interesante para resaltar es que, al efectuar un análisis retrospectivo de estos fallos, se puede apreciar cómo el tribunal constitucional progresivamente ha ampliado su campo de acción con respecto a la protección de derechos de las personas desplazadas, pues en 1997 las órdenes se dirigían a funcionarios y entidades específicas, y las soluciones propuestas se encaminaban a casos individuales de víctimas. Entre el 2000 y el 2003, los fallos contaban con un campo de cobertura más amplio dirigido hacia toda la población desplazada y efectuaban una valoración general a los mecanismos de atención (Rodríguez, 2009).

Con respecto a la declaratoria del ECI, como lo señala Botero (2006), la Corte Constitucional, en trámite de tutela, puede proferir sentencias con efectos inter partes que vinculan directamente a las partes del proceso; también puede producir fallos con efectos inter pares, en los cuales se establece que la regla que en la sentencia se define, debe aplicarse en el futuro a todos los casos similares. Otra posibilidad es que la sentencia tenga efectos inter comunis, lo que se traduce en que el alcance de sus efectos benefician a terceros que, pese a no formar parte del proceso, comparten circunstancias comunes a los accionantes en él. Finalmente, una cuarta opción para la Corte la constituye la declaratoria del ECI mediante la cual se ordena la adopción de programas destinados a beneficiar a personas que no interpusieron la acción de tutela, pero que se encuentran en circunstancias estructurales que representan la violación de derechos de un número plural y significativo de personas.

En consecuencia, esta última posibilidad fue la que seleccionó la Corte Constitucional, atendiendo a lo indicado en informes aportados por los diferentes organismos nacionales y locales desde donde se logró establecer que la población desplazada se encontraba en 
condiciones precarias, pues las acciones públicas de atención encaminadas a proteger a esta población resultaban insuficientes para superar el estado de deterioro de sus condiciones de vulnerabilidad.

Además, se afectaba el goce efectivo de sus derechos constitucionales, al no permitir que se superaran las condiciones que causan la violación de sus derechos. Para ello, la Corte mostró resultados estadísticos, como, por ejemplo, que "el $92 \%$ de la población desplazada presenta necesidades básicas insatisfechas (NBI)"; además, que "el $80 \%$ se encuentra en situación de indigencia"; asimismo, "el $63.5 \%$ de la población desplazada tiene una vivienda inadecuada y el $49 \%$ no cuenta con servicios idóneos". Sobre el asunto alimentario, se concluyó que los hogares desplazados "solo consumen el $43 \%$ de los niveles recomendados por el PMA". En el área educativa, "se encontró que el $23 \%$ de los niños y niñas menores de seis años [...] están por debajo del estándar alimenticio mínimo", lo que se ve reflejado en un estado de desnutrición que provoca un retraso de su talla y del peso ideal, junto con déficit de atención, predisposición a enfermedades, afectación a la visión e incremento de los casos de morbilidad infantil (C. C., Sentencia T-025-2004, Colom.).

En la misma sentencia de tutela con respecto a la garantía del derecho a la educación, el panorama no es mejor, pues "se observa que el $25 \%$ de los niños y niñas entre 6 y 9 años no asiste a un establecimiento escolar" y en relación con la población que se encuentra entre los 10 y 25 ańos, el porcentaje asciende a un 54\%. Concluye la Corte que, en el tema de la salud, la atención es precaria: como resultado de la insuficiencia de atención, se registra una tasa de mortalidad para la población desplazada que es seis veces superior al promedio nacional.

Frente a este escenario, la Corte mantuvo jurisdicción sobre el tema y dispuso efectuar un seguimiento a la actuación que le corresponde al Estado después de la Sentencia T-025 del 2004; en virtud de ello, emitió numerosas y precisas órdenes, entre las que se destacan tres principalmente:

1. Creación de un plan de acción tendiente a superar ECI, mediante el cual se efectúe una recolección y sistematización de la información básica sobre la situación de la población desplazada; la elaboración de un cálculo aproximado del presupuesto necesario para satisfacer las necesidades más urgentes de este 
grupo poblacional; identificación de las potenciales fuentes de las que se pudiera obtener el presupuesto para cumplir ese propósito y también la manera en que se distribuirían las responsabilidades presupuestales entre el nivel central y las entidades territoriales, tales órdenes se impartieron a las entidades públicas encargadas de adelantar la política en materia de desplazamiento forzado y que hacían parte del Consejo Nacional de Atención Integral a la Población Desplazada (CNAIPD), todo ellos en un plazo de dos meses.

2. Propuso la realización de todos los esfuerzos posibles para la consecución del presupuesto necesario para dar respuesta a las necesidades de los desplazados, en este caso, fijó como plazo, el término de un año.

3. Finalmente, la garantía del goce efectivo de los derechos básicos de las víctimas del desplazamiento. En este contexto, y acudiendo a las obligaciones constitucionales e internacionales del Estado, se fijaron como garantías: 1) el derecho a la vida; 2) el derecho a la dignidad y la integridad personas; 3) el derecho a la familia y la unidad familiar, 4) el derecho a la subsistencia; 5) el derecho a la salud básica; 6) el derecho a la no discriminación; 7) el derecho de los niños a la educación básica; 8) el derecho a la asesoría para la estabilización socioeconómica y; 9) el derecho a decidir libremente en cuanto al retorno al lugar de origen o a permanecer en el lugar de desplazamiento. Para el logro de estas metas, se fijó un plazo de seis meses. (Rodríguez, 2009, p. 27)

Al mismo tiempo que se declaraba el ECI y se impartían órdenes a las autoridades para la superación de esta problemática, se continuó con un proceso de seguimiento a la Sentencia T-025 del 2004. En tal sentido, durante los años siguientes al pronunciamiento de la Corte, se adelantó un proceso de seguimiento sobre su ejecución, por medio de la celebración de audiencias públicas y la expedición de autos de seguimiento. Esta labor ha contado, además, con el acompañamiento de organismos internacionales, organizaciones no gubernamentales, entidades académicas y, por supuesto, la intervención permanente de los órganos de control de la nación, así como de las entidades de los niveles central y local.

En desarrollo de este proceso, entre febrero del 2004 y diciembre del 2009 se dictaron 84 autos de seguimiento a las órdenes impartidas a las autoridades para que se tomaran los correctivos necesarios y se desarrollarán los debidos programas planteados en la Sentencia 
T-025 del 2004 (Rodríguez, 2009). Asimismo, en el período comprendido entre enero del 2010 y junio del 2017 se profirieron en total 266 autos mediante los cuales se solicitaron informes y acciones concretas, además de establecer indicadores de evaluación del grado de realización de los derechos de la población desplazada (C. C., Seguimiento al cumplimiento de la Sentencia T-025 del 2004).

Considerando el número significativo de autos de seguimiento que ha expedido la Sala Especial, vale resaltar lo que el propio Tribunal ha dado a conocer a la opinión pública a través de distintos pronunciamientos, cuando ha señalado que

[...] a lo largo del proceso de seguimiento, particularmente en los ańos 2008 y 2009, la Corte Constitucional expidió distintos autos cuyas órdenes estaban encaminadas a lograr la protección especial de la población más vulnerable al interior de la población desplazada, es decir, las mujeres (auto 092 de 2008); los nińos, niñas y los adolescentes (auto 251 de 2008); las comunidades afrodescendientes (auto 005 de 2009) e indígenas (auto 004 de 2009); y las personas con discapacidad y adultos mayores (auto 006 de 2009). Por medio de estos autos se buscó que la atención de la población desplazada fuera sensible a las particularidades que son propias de cada uno de estos grupos, lo cual incluye prevenir y atender determinados riesgos diferenciados que el desplazamiento forzado produce en cada caso. (C. C., Seguimiento al cumplimiento de la Sentencia T-025 del 2004)

Entre las principales decisiones dentro del proceso de seguimiento que efectúa la Corte al cumplimiento de las órdenes impartidas en la Sentencia T-025 del 2004, la más reciente está contenida en el Auto 373 del 23 de agosto del 2016. En este documento se formula una evaluación con respecto a los avances, estancamientos y retrocesos en cuanto a la protección y atención a la población desplazada, en el marco del seguimiento a los autos 008 del 2009, 385 del 2010 y 219 del 2011. Al respecto, señala la Sala:

Como resultado de la evaluación que adelanta esta la Sala Especial, se encontró que en los componentes de participación y de registro las autoridades acreditaron un nivel de cumplimiento alto a la orden de realizar ajustes importantes para avanzar en el goce efectivo de los derechos de la población desplazada. Con ello, 
esta Corporación declaró la superación del Estado de Cosas Inconstitucional en relación con ambos componentes, en la medida en la que cumplen con los estándares constitucionales definidos para cada uno de ellos. Con excepción del registro para pueblos y comunidades étnicos. Si bien los demás componentes no logran satisfacer los requisitos para hacer una declaratoria semejante, toda vez que no alcanzan los umbrales establecidos en la parte general del pronunciamiento, la Sala encontró los siguientes niveles de cumplimiento a las principales órdenes dictadas a lo largo del proceso de seguimiento.

En relación con aquellos componentes de la política cuya reformulación total fue ordenada en el 2009, los resultados alcanzados fueron los siguientes. La política de tierras presenta un nivel de cumplimiento dispar: mientras el gobierno nacional ha demostrado un nivel de cumplimiento alto en materia de restitución de tierras, en lo concerniente a su protección se ha presentado un evidente nivel de incumplimiento; en materia de vivienda urbana y rural las autoridades han demostrado un nivel de cumplimiento medio y bajo, respectivamente y, en generación de ingresos, se registró un incumplimiento a la orden de reformular completamente esta política.

Por su parte, los componentes cuya complementación fue ordenada para así articularse y superar los vacíos protuberantes que los afectaban, a saber: prevención y protección, y los derechos a la verdad, la justicia, la reparación y las garantías de no repetición, arrojaron un nivel de cumplimiento bajo.

Finalmente, en lo atinente a los demás componentes que requieren importantes avances para lograr el goce efectivo de los derechos de las personas desplazadas los resultados fueron los siguientes: en ayuda humanitaria las autoridades acreditaron un cumplimiento medio; en retornos y reubicaciones el cumplimiento es bajo y en educación el cumplimiento es medio. (C.C., Seguimiento al cumplimiento de la Sentencia T-025 del 2004)

El resultado más importante de la labor adelantada por la Corte Constitucional es la creación de un espacio participativo y de seguimiento permanente y detallado respecto del cúmulo de órdenes que dictó a las diferentes entidades del orden central y territorial para remediar el grave estado de vulnerabilidad de la población desplazada. Se destacaban las 
fallas recurrentes, la inadecuada protección ofrecida a los desplazados, el escaso presupuesto para mitigar sus necesidades y la ausencia de indicadores que permitieran establecer el grado de goce efectivo de los derechos de este grupo poblacional. En tal sentido, como lo recuerda Rodríguez , el resultado del activismo de la Corte permitió la creación de "una lista de 20 derechos que pueden ser evaluados a partir de unos indicadores de resultado de tres tipos: goce efectivo de derechos, complementarios y sectoriales" (2009, p. 31).

De manera breve, se enuncian los indicadores de resultado adoptados por la Corte Constitucional que se reconocen a los desplazados forzados (Rodríguez, 2009, pp. 460-473):

1. Derecho a la vida.

2. Derecho a la integridad personal.

3. Derecho a la libertad.

4. Derecho a la vivienda.

5. Derecho a la salud

6. Derecho a la educación.

7. Derecho a la alimentación.

8. Derecho a la generación de ingresos.

9. Derecho a tener una identidad.

10. Derecho a la estabilidad social y económica.

11. Derecho a la prevención del desplazamiento.

12. Derecho al retorno. 
13. Derecho a la subsistencia.

14. Derecho a la reunificación familiar.

15. Derecho a la seguridad personal.

16. Derecho a la participación.

17. Derecho a la verdad, la justicia, la reparación y la no repetición.

18. Enfoque diferencial: niños, niñas y adolescentes desplazados.

19. Enfoque diferencial: permanencia étnica y cultural.

20. Enfoque diferencial: género.

Como puede apreciarse, en este caso particular, la Corte asumió un notorio activismo en procura de garantizar el reconocimiento y la protección efectiva de los derechos de la población desplazada. Pese a algunos importantes avances que se han dado desde la declaratoria del ECI, aún no se ha logrado en su integridad la satisfacción efectiva y una eventual superación del ECI por parte de las autoridades correspondientes (Llano, 2013).

En este contexto, como lo recuerda García Villegas (2014), existe una relación entre el efecto de las decisiones judiciales y las prácticas sociales emancipadoras que no se refiere a una relación directa, pues para determinar el alcance de una decisión judicial, es indispensable determinar el contexto en que esta se presenta, lo que permite establecer su alcance como emancipación social. Así, pueden mencionarse dos tipos de activismo social. Uno de ellos corresponde a aquel mediante el cual el juez reconoce derechos que resultan controvertidos por sectores políticos para los cuales esos derechos no derivan ciertamente del ordenamiento jurídico. En este escenario, se hablaría de activismo “jurisprudencial”, mediante el cual se declara judicialmente la existencia de valores o se confieren derechos a grupos sociales específicos. En tal caso, se habla de activismo valorativo o ideológico. 
Por otra parte, se habla de un activismo remedial, que se presenta cuando, de las decisiones que toman los jueces - pese al reconocimiento del derecho y su aceptación por parte de la sociedad - resultan críticas que consideran que sus fallos se extralimitan e invaden las competencias de otros órganos del Estado, a los que realmente correspondería adoptar los remedios judiciales correspondientes. En Colombia, un ejemplo de esta realidad es el que se da con las condiciones infrahumanas en que se encuentran las personas privadas de la libertad (García Villegas, 2014).

Para efectuar la evaluación en cuanto al grado de satisfacción y superación de los programas establecidos, en razón de las órdenes impartidas por la Corte, se creó la Comisión de Seguimiento, que asumió dicha labor mediante el diseño e implementación de una Encuesta Nacional de Verificación (ENV), definida como "un instrumento metodológico de carácter independiente, que con base en información primaria, permite desarrollar una estricta estimación estadística de los indicadores de goce efectivo de derechos" (Guerrero, Guerrero, y Nisimblat, 2010).

La condición de vulnerabilidad de la población desplazada aún persiste. A tal conclusión se llega después de analizar los resultados a la Tercera Encuesta Nacional de Verificación 2010, que permite tener una visión actualizada respecto de las características y condiciones de la población desplazada y el cumplimiento de los programas propuestos. Así, "resulta claro que sus condiciones de vida siguen siendo extremadamente precarias y que se está lejos de garantizar el goce efectivo de sus derechos" (Garay, 2011, p. 231).

Expone Garay (2011) que esta condición tiende a perdurar en el tiempo, debido a que se ha evidenciado que los factores constitutivos que incrementan la vulnerabilidad de la población desplazada no evolucionan favorablemente. Asíse desprende de los rasgos más notorios que presentan las familias desplazadas, al contar con hogares de mayor tamaño relativo, con un promedio de cinco personas, que en su mayoría corresponden a jóvenes (66\% de las personas son menores de 25 años). Además, la jefatura en la mayoría de los hogares es asumida por mujeres solas ( $49 \%$ de los hogares con jefe desplazado). Persiste la condición de niveles bajos en educación; así mismo, y en concordancia con lo revelado por la Segunda Encuesta Nacional de Verificación 2008, una proporción elevada de personas se identificaron como pertenecientes a algún grupo étnico, principalmente desplazados y afrodescendientes. 
La Comisión de Seguimiento puedo constatar por medio de encuestas que algunos componentes de los subsistemas de derechos en atención, derechos fundamentales y de autosostenibilidad se han cumplido, pero "en términos generales puede afirmarse que entre los años 2008 y 2010 no se evidenciaron cambios significativos en la mayoría de los indicadores del goce efectivo de los derechos de la población desplazada" (Garay, 2011, p. 231).

Por otra parte, señala Calle (2016) que, a pesar de la persistencia de deficiencias en cuanto al avance en la ejecución de programas de atención y protección de la población desplazada, la función de la Corte ha sido determinante a la hora de evaluar la utilidad e importancia del mecanismo de seguimiento que viene adelantado el alto tribunal. En consecuencia, las cifras reflejan alguna mejoría (tablas 2 y 3 ):

Tabla 2. Incremento de recursos destinados para la atención a la población desplazada (valores en Cor)

\begin{tabular}{lccccc} 
Período (trianual) & 1999 a 2002 & 2003 a 2006 & 2007 a 2010 & 2011 a 2014 \\
\hline Monto total & 498855 & 2 billones & 4.6 billones & 54 billones \\
\hline
\end{tabular}

Fuente: elaboración propia con base en el Anuario de Derecho Constitucional Latinoamericano (2016).

Tabla 3. Indicadores de goce efectivo (en porcentajes)

\begin{tabular}{lcc}
\multicolumn{1}{r}{ Indicador/período } & $\mathbf{2 0 1 0}$ & $\mathbf{2 0 1 3}$ a 2014 \\
\hline Acceso a alimentos necesarios & 90.28 & 93.5 \\
\hline Acceso a vivienda digna & 16.14 & 19.15 \\
\hline Acceso a educación & 75.74 & 87.8 \\
Derecho a la vida & 98.76 & 98.9 \\
\hline
\end{tabular}

Fuente: elaboración propia con base en el Anuario de Derecho Constitucional Latinoamericano (2016).

Por consiguiente, a pesar de observarse una ambivalencia en cuanto al avance en algunos aspectos y el estancamiento en otros, la labor de la Corte permite apreciar que 
[...] la Sentencia T-025 de 2004 y el proceso institucional de seguimiento han tenido, ante todo, un efecto simbólico, Las personas desplazadas ahora son consideradas como víctimas de una vulneración masiva, reiterada y prolongada de sus derechos humanos, y no como migrantes voluntarios [...]. Las personas desplazadas tienen ahora el poder del discurso de los derechos y una decisión de la Corte que declara que su situación es inconstitucional, por lo cual merecen toda la protección y garantía posibles del Estado y sus instituciones. Las personas desplazadas tienen además una jerarquía en el Estado, que está abierta a escuchar sus reclamos y a responder, en la medida de las posibilidades, para que el Estado reaccione. (Calle, 2016, pp. 458-459)

Un aspecto que reviste especial importancia al momento de lograr la efectividad en la implementación y ejecución de los programas de atención a la población desplazada es el relacionados con la interacción que debe existir entre los territorios y el nivel central. Pese a los esfuerzos por consolidar una política que responda a las reales necesidades de la población desplazada (Rincón y Peñas, 2015), se requiere aunar esfuerzos entre amplios sectores gubernamentales, a fin de garantizar el goce efectivo de los derechos conculcados a los sectores marginados de la sociedad. Vale la pena resaltar lo que al respecto ha expuesto Torres:

[...] la experiencia en el tema de desplazamiento forzado ha sido enriquecedora para mostrar los desafíos y fallas que se presentan a la hora de coordinar una política pública de derechos humanos que tiene hondas implicaciones internacionales y su materialización sobre el territorio. En el desarrollo de esta política, se han evidenciado problemas de coordinación intra e interinstitucionales tanto en los niveles nacionales como locales, corrupción en el manejo de los dineros y programas de atención, desconocimiento de los funcionarios que tienen a su cargo estas responsabilidades, deficiencias en la gestión y gerencia de estos programas, entre otros.

Ante esta situación se presenta una clara tensión entre quienes afirman que producto de los procesos de descentralización son los entes territoriales los que deben asumir varias de las obligaciones que se adjudican frente a los derechos 
Luisa Fernanda García Lozano, Luis Alberto Castellanos Castillo

de las víctimas, y los que señalan que la descentralización no significa que el gobierno nacional pueda descargar el pleno de estas responsabilidades en las regiones. La precariedad de algunos municipios colombianos muestra la necesidad de intervención de nación, pero, por otra parte, esta intervención puede socavar los objetivos planteados en la Constitución nacional frente a la descentralización y la autonomía regional. (2013, p. 320)

\section{A MOdo DE CONCLUSIÓN}

Si bien el gobierno nacional, para la década de los noventa, momento en el cual empezaba a tomar unas dimensiones verdaderamente complejas el desplazamiento forzado, y pese a que en un primer momento no logró establecer una estrategia pública lo suficientemente sólida, incluyente y completa, con el transcurrir de los años y también debido en gran parte al activismo de la Corte Constitucional, ha expedido algunas leyes que sumadas a los fallos de tutela, principalmente, han permitido visibilizar y ofrecer unos mecanismos efectivos al momento de brindar protección a los derechos de las personas víctimas de la violencia.

Como ya se ha mencionado, la ejecución y los efectos materiales de la Ley 1448 del 2011 están sujetos a la suficiencia presupuestal para cumplir lo que se propone, a pesar de tener como propósito el establecimiento de medidas de asistencia y mecanismos de reparación integral en el contexto del conflicto armado. De ello puede afirmarse que el cumplimiento de las medidas de reparación administrativa se encuentran condicionadas a la existencia de recursos fiscales suficientes que permitan dotar de eficacia su sustentabilidad en el tiempo, pues no puede desconocerse que el elevado número de víctimas del conflicto armado, que ronda casi los nueve millones, requieren una asignación económica para satisfacer sus derechos, lo que demanda al gobierno nacional el diseño y ejecución de directrices macroeconómicas que deben ajustarse a la realidad del país en este ámbito.

Un elemento que puede resaltarse es el relacionado con la intención que tuvo la Corte Constitucional al proferir la Sentencia T-025 del 2004, en el entendido de que esta constituye un instrumento a través del cual se evidenció el activismo judicial del tribunal constitucional. Aunado a la sentencia, la celebración de audiencias públicas, la 
conformación de una Comisión Especial de Seguimiento a la Política Pública sobre Desplazamiento Forzado y la expedición de un número importante de autos de seguimiento parecería indicar que las aspiraciones legales y constitucionales de mitigar los efectos del desplazamiento forzado y de dar por superado el ECI en este ámbito aún distan mucho de cumplir su propósito.

Siguiendo lo expresado por García Lozano, a pesar de los efectos sustanciales que procuran los autos emitidos por la Corte mediante los cuales se ordena la adopción de políticas públicas, estos resultan contrarios a las funciones que debe cumplir el alto tribunal; no obstante, representan una oportunidad para los grupos poblacionales más vulnerables. En tal sentido, ante la falta de coherencia en las medias adoptadas, así como en las funciones asignadas para brindar atención y protección a la población desplazada, "tal como lo demostró la sentencia T-025 del 2004 hacen que el Estado se constituya en un Estado fracasado y la Corte Constitucional con sus acciones, aunque loables sean parte de un imaginario simbólico" (García Lozano, 2014, p. 165).

En definitiva, además de la destinación de recursos suficientes para atender las necesidades fundamentales y básicas de la población desplazada, entre las que se cuenta la reparación por vía administrativa, lo que se requiere es el diseño de planes incluyentes y ajustados a las condiciones reales de este grupo poblacional. Hasta el momento, la labor de la Corte ha sido importante, pero debe tenerse en cuenta que si bien "la interpretación constitucional se ocupa especialmente de las disposiciones de derechos fundamentales de una Constitución, los cuales tienen que ser armonizados con otras normas constitucionales sobre la organización estatal y el orden económico” (Arango, 2012, p. 138), para lograr la efectividad de los derechos sociales fundamentales es necesario propiciar la generación de medidas públicas estructuradas y realmente eficaces. Estas deben ajustarse a las dinámicas del mercado e incidir de manera significativa en la protección real, más que ideal, de estos derechos. En este escenario aún falta mucho por hacer, pues el desplazamiento forzado, como pudo apreciarse, es el fenómeno social que reúne el mayor número de víctimas y, por lo tanto, es el que demanda un considerable volumen de asignación presupuestal. 
Luisa Fernanda García Lozano, Luis Alberto Castellanos Castillo

\section{REFERENCIAS}

Alzate, V. y Rodríguez, J. (2017). Análisis de la gestión de políticas y procesos burocráticos en la atención a las víctimas de la violencia en Colombia. Ciencia Política, 12(23), 23-55.

Arango, R. (2012). La justiciabilidad de los derechos sociales fundamentales. Legis.

Arias, M., Camacho, A., Ibañez, A., Mejía, D. y Rodríguez, C. (2014). Costos económicos y sociales del conflicto en Colombia. ¿Cómo construir un posconflicto sostenible? Bogotá: Ediciones Uniandes.

Bello, M. (2004). Desplazamiento forzado. Dinámicas de guerra, exclusión y desarraigo (Universida). Bogotá: Universidad Nacional de Colombia; Oficina del Alto Comisionado de las Naciones Unidas para los Refugiados. Recuperado de http://www.bdigital.unal.edu. co/7258/1/aurapatriciabolivarjaime.2012.pdf

Bolívar, A. (2012). Programas administrativos de reparación: El caso colombiano en perspectiva comparada. Bogotá: Repositorio Universidad Nacional de Colombia Sede Bogotá. Recuperado de http://www.bdigital.unal.edu.co/7258/1/aurapatriciabolivarjaime.2012.pdf

Botero, C. (2006). Trámite de la acción de tutela y facultades del juez constitucional. Bogotá: Escuela Judicial Rodrigo Lara Bonilla, Consejo Superior de la Judicatura.

Calle, M. (2016). La constitución en marcha: el cumplimiento de sentencias estructurales en la Corte Constitucional colombiana. En M.-C. Fuchs y C. Steiner (Eds.), Anuario de Derecho Constitucional Latinoamericano, 2016 (pp. 449-459). Bogotá: Fundación Konrad Adenauer. Recuperado de http://www.kas.de/wf/doc/kas_46909-1522-4-30. pdf?161104181217

Colombia. Acto legislativo 03 de 2011. Por el cual se establece el principio de la sostenibilidad fiscal. 1 de julio de 2011. D. O. 48117.

Comisión Histórica del Conflicto y sus Víctimas. (2015). Contribución al entendimiento del conflicto armado en Colombia. Bogotá: Comisión historica del conflicto y sus victimas.

Comité Internacional de la Cruz Roja. (1998). Principios Rectores de los desplazamientos internos. Revista Internacional de La Cruz Roja. Recuperado de https://www.icrc.org/ spa/resources/documents/misc/5tdmhb.htm 
Díaz, C. (2010). Tareas pendientes: propuestas para la formulación de politicas públicas de reparación en Colombia. Opciones Gráficas Editores.

Díaz, V. y Leiva, P. (2009). La gente de nadie: desplazamiento forzado (Universidad del Rosario, Bogotá). Universidad del Rosario (Bogotá). Recuperado de http://repository.urosario.edu.co/bitstream/handle/10336/1256/1019005462.pdf?sequence=1

Garay, J. (2011). El reto ante la tragedia humanitaria del desplazamiento forzado. Garantizar la observancia de los derechos de la población desplazada II. Bogotá: Corcas.

García Londońo, C. (2014). Concepto de justicia en la Ley de víctimas y restitución de tierras. (Proyecto de maestría en filosofia y política). Pereira. Recuperado de http://repositorio.utp. edu.co/dspace/bitstream/handle/11059/5077/34403288G216.pdf?sequence=1

García Lozano, L. (2014). Los autos de seguimiento de la Corte Constitucional: ¿la constitución de un imaginario simbólico de la justicia por parte de la Corte? Análisis Político, (82), 149-166. https://doi.org/https://doi.org/10.15446/anpol.v27n82.49412

García Villegas, M. (2014). La eficacia simbólica del derecho: sociología politica del campo juridico en América Latina. Bogotá: Penguin Random House.

Gómez, J. (2015). El criterio de sostenibilidad fiscal: un cuestionamiento sobre los efectos del Acto Legislativo 03 de 2011. Revista de Derecho Público, (35), 1-31. https://doi.org/ http://dx.doi.org/10.15425/redepub.35.2015.12

Guerrero, M., Guerreo, M. y Nisimblat, N. (2010). Indicadores de goce efectivo de derechos en familias desplazadas por la violencia en Colombia. Acción pública. Studiositas, 5(1), 39-59. Recuperado de http://repository.ucatolica.edu.co/bitstream/10983/577/1/ Stud_5-1_A04_guerrero-guerrero-nisimblat.pdf

Ibáñez, A. (2008). El desplazamiento forzoso en Colombia: ¿Un camino sin retorno a la pobreza? Bogotá: Ediciones Uniandes.

Ibarra, K. (2016). El confinamiento de la población civil, obligaciones y responsabilidad del Estado colombiano. Hecho victimizante autónomo frente al desplazamiento forzado. Bogotá: Universidad Nacional de Colombia. Recuperado de http://www.bdigital.unal.edu. co/54998/1/karenjohannaibarraarcos.2016.pdf

Kalmanovitz, S. (2011). La sostenibilidad fiscal. El Espectador. Recuperado de http://www. elespectador.com/opinion/la-sostenibilidad-fiscal-columna-266521 
Luisa Fernanda García Lozano, Luis Alberto Castellanos Castillo

Leaño, A. (2015). Modelo de acumulación colombiano: génesis del conflicto armado colombiano. De Prácticas y Discursos. Cuadernos de Ciencias Sociales, 4(4), 1-11. Recuperado de http://ppct.caicyt.gov.ar/index.php/depracticasydiscursos/article/view/7237

Llano, J. (2013). Prácticas jurídicas locales desde los actores del conflicto armado en Colombia. IUSTA, 39(2), 257-287.

López, G. (2012). Los derechos sociales en Colombia y el principio de sostenibilidad fiscal. Revista Dixi, 14(15), 22-39.

López, M. (2014). Desplazamiento forzado y Consejo de Estado. Un juez amplio considerando pero tímido fallando. Estudios Socio-Jurídicos, 16(2), 127-162. https://doi.org/ dx.doi.org/10.12804/esj16.02.2014.04

Lozano, M. A., Payán, A. S. y Ruiz, L. E. (2015). La discusión probatoria de las víctimas y la Sentencia T-025 de 2004. En M. Torres y P. Iregui (Eds.), El desplazamiento forzado en Colombia: 10 años de la Sentencia T-025 de 2004 (pp. 39-60). Editorial Universidad del Rosario.

Morales, D. (2012). Corte Constitucional y cambios en la Política de Atención a la Población Desplazada por la Violencia: una mirada al activismo judicial desde el enfoque institucional. Con-Texto, (38), 55-85. Recuperado de http://revistas.uexternado.edu.co/index. $\mathrm{php/contexto/article/view/3317}$

Organización de Estados Americanos; Comisión Interamericana de Derechos Humanos. (1999). Tercer Informe sobre la situación de derechos humanos en Colombia; Capítulo III, Los derechos económicos, sociales y culturales. Recuperado de https://www.hchr. org.co/documentoseinformes/documentos/html/informes/osi/cidh/CIDH 3er Informe Colombia capitulo-4a.html

Rincón, K. y Peñas, A. (2015). El delito político en Colombia frente al derecho internacional humanitario. IUSTA, (43), 67-90.

Rodríguez, C. (2009). El contexto: el desplazamiento forzado y la intervención de la Corte Constitucional (1995-2009). En C. Rodríguez (Ed.), Más allá del desplazamiento. Políticas, derechos y superación del desplazamiento forzado en Colombia (pp. 14-35). Bogotá: Ediciones Uniandes. 
Romero, J. (2014). La precariedad de los derechos sociales de la población desplazada en un contexto de sostenibilidad fiscal. Analecta Política, 5(7), 345-367.

Rosas, G., Plazas, M. y Bernal, S. (2013). Sostenibilidad fiscal y regla fiscal: aspectos juridicos y económicos. Bogotá: Instituto Colombiano de Derecho Tributario.

Torres, J. (2013). Las regiones frente a la justicia transicional. Estudios de Derecho, 70(155), 314-338.

Unidad para la Atención y Reparación Integral a las Víctimas. (2020). Reporte general de víctimas. Recuperado de https://cifras.unidadvictimas.gov.co/Home/General

Villabella, C. (2015). Los métodos en la investigación jurídica: algunas precisiones. Universidad Nacional Autónoma de México: Instituto de Investigaciones Jurídicas. Recuperado de https://archivos.juridicas.unam.mx/www/bjv/libros/8/3983/46.pdf 